\title{
Solvent extraction of uranium from leach solutions obtained in processing of Polish low-grade ores
}

\author{
Katarzyna Kiegiel $^{1}$ - Anna Abramowska ${ }^{1}$ Paweł Biełuszka ${ }^{1}$. \\ Grażyna Zakrzewska-Kołtuniewicz ${ }^{1} \cdot$ Stanisław Wołkowicz $^{2}$
}

Received: 24 June 2016/Published online: 14 September 2016

(c) The Author(s) 2016. This article is published with open access at Springerlink.com

\begin{abstract}
Solvent extraction of uranium from acidic and alkaline post-leaching liquors that were obtained by leaching of Polish ores is reported in this paper. The stripping of uranium from organic to aqueous phase was also studied. The synergistic mixture of 2-diethylhexylphosphoric acid (D2EHPA) and tri- $n$-butylphosphate (0.2 M:0.2 M) was found as a good extracting agent for uranium. Recovery of uranium was reached even $98 \%$. The effect of such parameters like uranium concentration and concentration of reagents used in the experiments was evaluated in advance by using a model uranium solutions.
\end{abstract}

Keywords Uranium - Sandstones - Geochemical analysis · Solvent extraction

\section{Introduction}

Uranium was extracted from the raw material in complex hydrometallurgical processes involving many separation steps. Processes such as solid-liquid extraction, solvent extraction, and ion exchange are applied to obtain pure triuranium octaoxide $\left(\mathrm{U}_{3} \mathrm{O}_{8}\right)$ from uranium ore [1]. Since in most of uranium minerals uranium is accompanied by other heavy metals, post-leaching liquors usually contain a mixture of different metal ions that should be separated from $\mathrm{UO}_{2}{ }^{2+}$. Solvent extraction is a versatile technique for

Katarzyna Kiegiel

k.kiegiel@ichtj.waw.pl

1 Institute of Nuclear Chemistry and Technology, Dorodna 16, 03-195 Warsaw, Poland

2 Polish Geological Institute National Research Institute, Rakowiecka 4, 00-975 Warsaw, Poland separating ionic solutes. The uranyl ion forms complexes with various organic chelatic agents. Nowadays, the literature reports a great variety of extractants that have been used for the extraction of uranium from aqueous solutions [2-4]. The most of them are the nitrogen-based, phosphorous-based and sulphur-based extractants. Among these neutral organophosphorus extractants tri- $n$-butylphosphate (TBP) probably received the most attention and use of this solvent on a commercial scale for the recovery of uranium (VI) from its ores and spent nuclear fuel is well known [5]. However, the selectivity of TBP is not high, as well as its radiolytic stability. Other organophosphorus extractants, including bis-2-ethylhexyl phosphoric acid (HDEHP) are applied in technology of uranium production. The aim of these studies was a selection of the extracting agents appropriate for the recovery of uranium from acidic and alkaline post-leaching liquors that were obtained by leaching of Polish ores. The raw extractants, like e.g.: tributylphosphate (TBP), di(2-ethylhexyl) phosphoric acid (D2EHPA), trioctylphosphine oxide (TOPO), triethylamine (TEA), tri- $n$-octylamine (TnOA), etc. were tested, and separation of uranium from other metals present in leach solutions, and efficiencies of their extraction were determined. The effect of type of extractant, sulphuric acid and uranium concentrations on the extraction process from model solutions was investigated. The results of these experiments were further used for the extraction of uranium from real post-leaching liquors. The use of different reagents as strip solutions selected on the basis of the literature data was also investigated [6,7]. Stripping agents such as sodium carbonate solution, ammonium carbonate solution, sulphuric acids were tested for recovery of uranium from the organic phase.

One of the main elements in the development of nuclear energy is knowledge concerning potential sources to supply 
uranium for nuclear fuel production. In every country the problem of security if raw resources, also in energy aspect, is the subject of geological surveys. In parallel to geological examination usually the research on the technology of recovery of useful ingredients is carried on. The same approach is in Poland. Conducted geological research, throughout Poland, allow to state that there are no reach and easily accessible uranium resources. For that reason into the researches included low grade uranium resources located in hard geological conditions. This study is one of the part of research on a much broader scale which also included aspects of uranium mining profitability of this type of deposit in Poland, leading to obtain yellow cake.

The most prospective uranium mineralization on the Polish territory is the lower and middle Triassic rocks of the central parts of Peribaltic Syneclise. However, it is situated at depths of at least $750 \mathrm{~m}$ so they have to be treated as prognostic or perspective $[8,9]$. The postleaching solution examined in this study were obtained by leaching of these rocks.

\section{Geochemical analysis of uranium-bearing Triassic sandstones from Peribaltic Syneclise}

The technological research based on natural rock samples have to be preceded by geochemical studies with determination of forms of useful element, its relation to other elements, both trace and major, and thus to examine the broader chemical context of environment in which examined element, in this case uranium, is present. Natural rock material is usually very diverse in geochemical aspect and the selection of one of known methods for processing have to be preceded by detailed geochemical tests.

Uranium mineralization in sandstones of Peribaltic Syneclise has typical epigenetic character. The characteristic features of sandstone-type uranium deposits are the significant vertical and horizontal variation zonation as well as zonal distribution of the trace elements associated with uranium.

From the point of view of uranium recovery technology its correlations with other metals, which may be the subject of simultaneous recovery during technological processes is very important. This might have an impact on improving the profitability of exploitation and processing of uranium ore because other metals which can be recovered will be co-product.

The concentration of metals was determined by using inductively coupled plasma mass spectrometry (ICP-MS). Uranium content in the analyzed samples was highly variable and ranges from $4.2 \mathrm{ppm}$ to nearly $1.5 \%$. The reason for this was that the samples come from strongly mineralized zones as well as from surrounding gangue rocks. The arithmetic mean of uranium content in the analyzed samples was $804 \mathrm{ppm}$, while the geometric mean was several times lower (138 ppm). The standard deviation characterized variability of set was very high and equals 2228 ppm. Histogram (Fig. 1) clearly illustrates polygenetic character of uranium mineralization.

Vanadium is an element which often accompanied by the uranium in this type deposits. Its content in the studied population was also highly variable and ranges from $33 \mathrm{ppm}$ to $0.46 \%$. The arithmetic mean was $362 \mathrm{ppm}$ and the geometric mean-195 ppm. The histogram of vanadium distribution is multimodal distribution (Fig. 2). It indicated the multi-stage formation of vanadium concentration in the rock. Main modal value was located in the class $50-100 \mathrm{ppm}$, which substantially corresponded to the background value: about $35 \mathrm{ppm}$ for sandstones and $130 \mathrm{ppm}$ for claystones. There were still quite numerous group of samples characterized by elevating content of vanadium, exceeding $300 \mathrm{ppm}$. Comparison of $\mathrm{U}$ and $\mathrm{V}$ distribution showed their similarity.

Selenium is an element associated with uranium mineralization in Triassic rocks of Peribaltic Syneclise. Its content ranges from $<1 \mathrm{ppm}$ (detection limit of the analytical method) to more than $0.43 \%$. The arithmetic average of Se content of this element was about $110 \mathrm{ppm}$, and the geometric mean is $4.5 \mathrm{ppm}$. Spot accumulation of selenium in the rock was manifested by the presence of its own mineral-clausthalite, which was identified in the mineralogical study. The lead content ranged from $6.8 \mathrm{ppm}$ to $0.62 \%$. The arithmetic mean of $\mathrm{Pb}$ content was $323 \mathrm{ppm}$, and the geometric mean was several times lower and was equal to $49 \mathrm{ppm}$. Histogram of the lead distribution is similar to the uranium one (compare Figs. 1, 3). It is multimodal, with clearly defined population samples, covering approximately $25 \%$ of the samples with relatively high contents of lead (200 ppm). This similarity

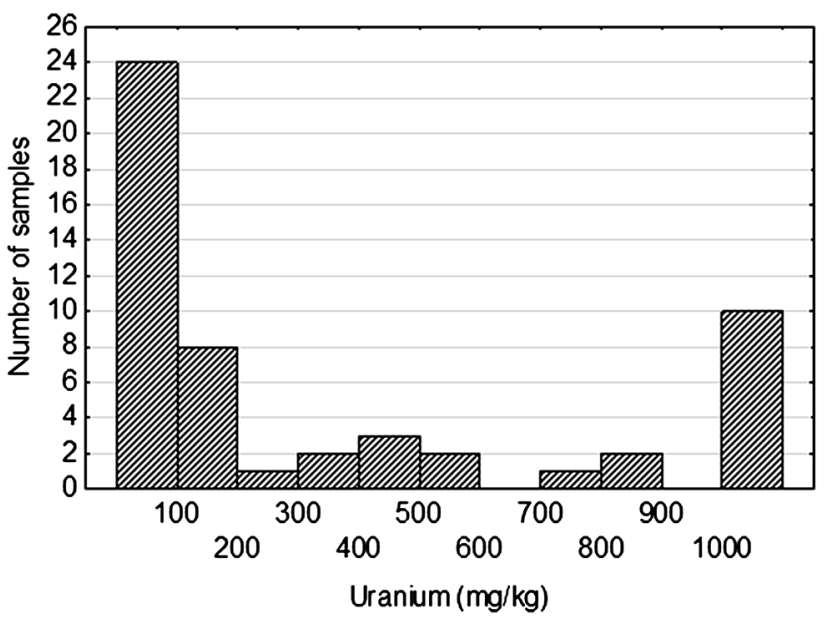

Fig. 1 Uranium distribution in Triassic sandstones 


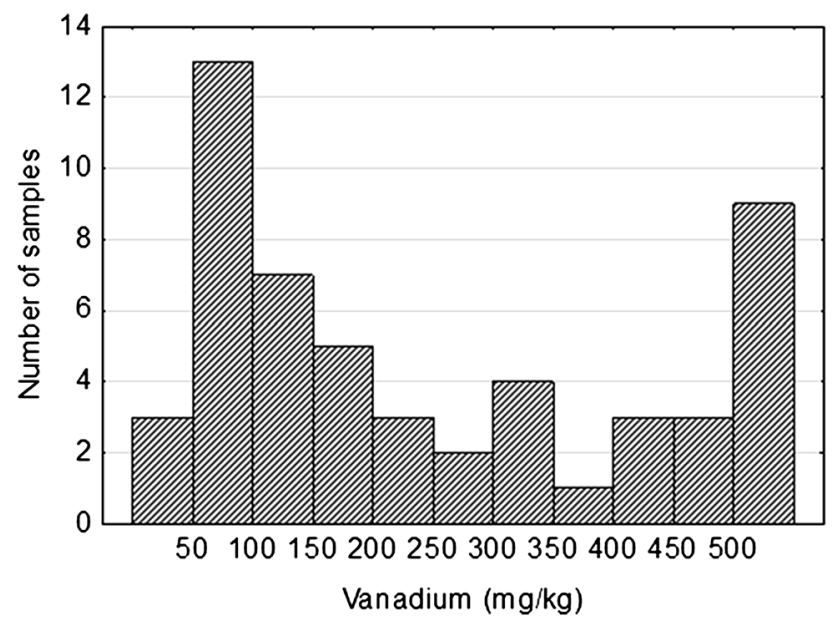

Fig. 2 Vanadium distribution in Triassic sandstones

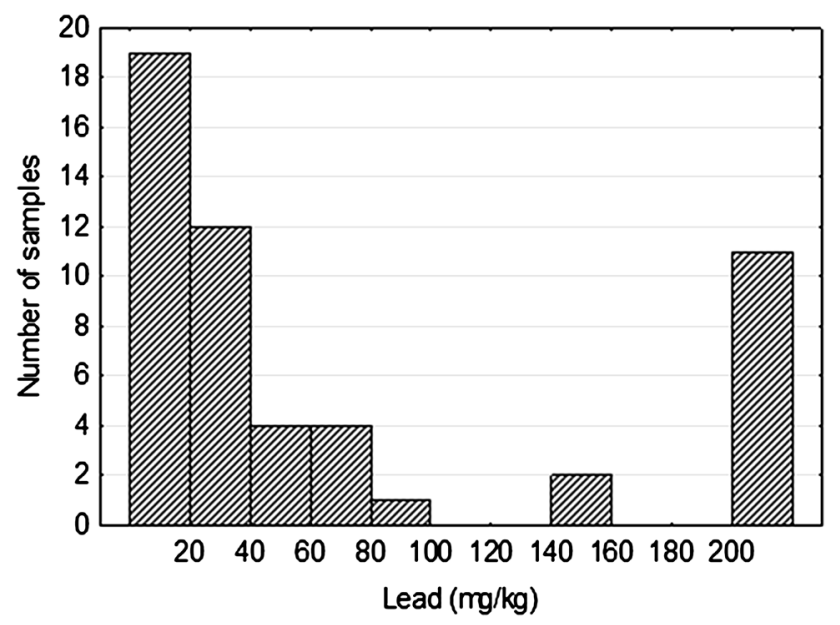

Fig. 3 Lead distribution in Triassic sandstones

might indicate the radiogenic origin of a large part of this element.

Thorium content in examined samples was low, ranging from 2.5 to $15.2 \mathrm{ppm}$. The arithmetic mean of Th content was 6.6 and the geometric mean of $5.8 \mathrm{ppm}$. These contents are typical of sandstone and reflect syngenetic nature of thorium presence in studied rocks. Histogram of distribution is practically unimodal, skewed right, the modal value is located in the bin from 2 to 4 ppm (Fig. 4). Differentiation of thorium content corresponds to the lithological variability of studied rock formation consisting mainly of sandstones with finer-grained inserts and interbeddings. Typically $\mathrm{Th} / \mathrm{U}$ ratio in sandstones varies from 3 to 4 . Using this ratio syngenetic uranium concentration should vary between 1 and $5 \mathrm{ppm} \mathrm{U}$. Thus, as a result of epigenetic processes mineralizing enrichment factor of uranium reached a few thousand.

From the other elements worth noting the silver. Its content ranged from 0.1 to $5.5 \mathrm{ppm}$. The arithmetic mean

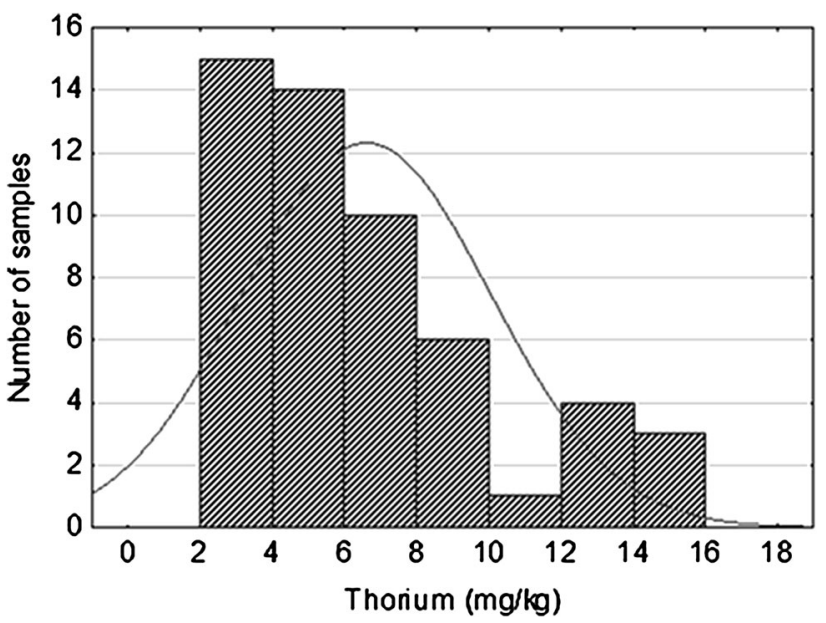

Fig. 4 Thorium distribution in Triassic sandstones

of $\mathrm{Ag}$ contents was $0.86 \mathrm{ppm}$ and the geometric mean was $0.47 \mathrm{ppm}$. Histogram of distribution indicates the presence of a dominant population with modal value located in the bin from 0 to $0.5 \mathrm{ppm}$, but more than $25 \%$ of the samples comprise silver in an amount from 0.5 to 2 ppm (Fig. 5). Furthermore, there was another group of samples $(8 \%$ of population) with silver contents ranging from 4 to $5.5 \mathrm{ppm}$. This indicated the presence of rocks clearly epigenetically enriched in silver.

In the studied rocks uranium showed the strongest correlation with lead (0.92), yttrium (0.93), silver (0.76), copper (0.75), antimony (0.70), and cobalt (0.44). It was negatively correlated with barium $(-0.43)$ and strontium $(-0.36)$ (Table 1). There was no correlation with vanadium, despite the fact that both of these elements certainly had epigenetic origin. This was due to the fact that uranium and vanadium anomalies have a different geometry: vanadium occurs mainly claystones and siltstones while the highest concentrations of uranium are associated with

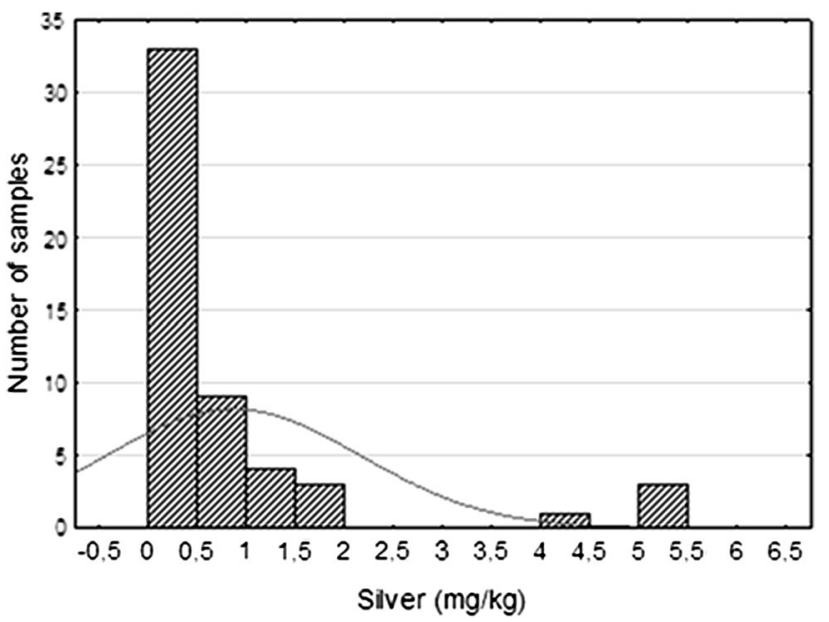

Fig. 5 Silver distribution in Triassic sandstones 


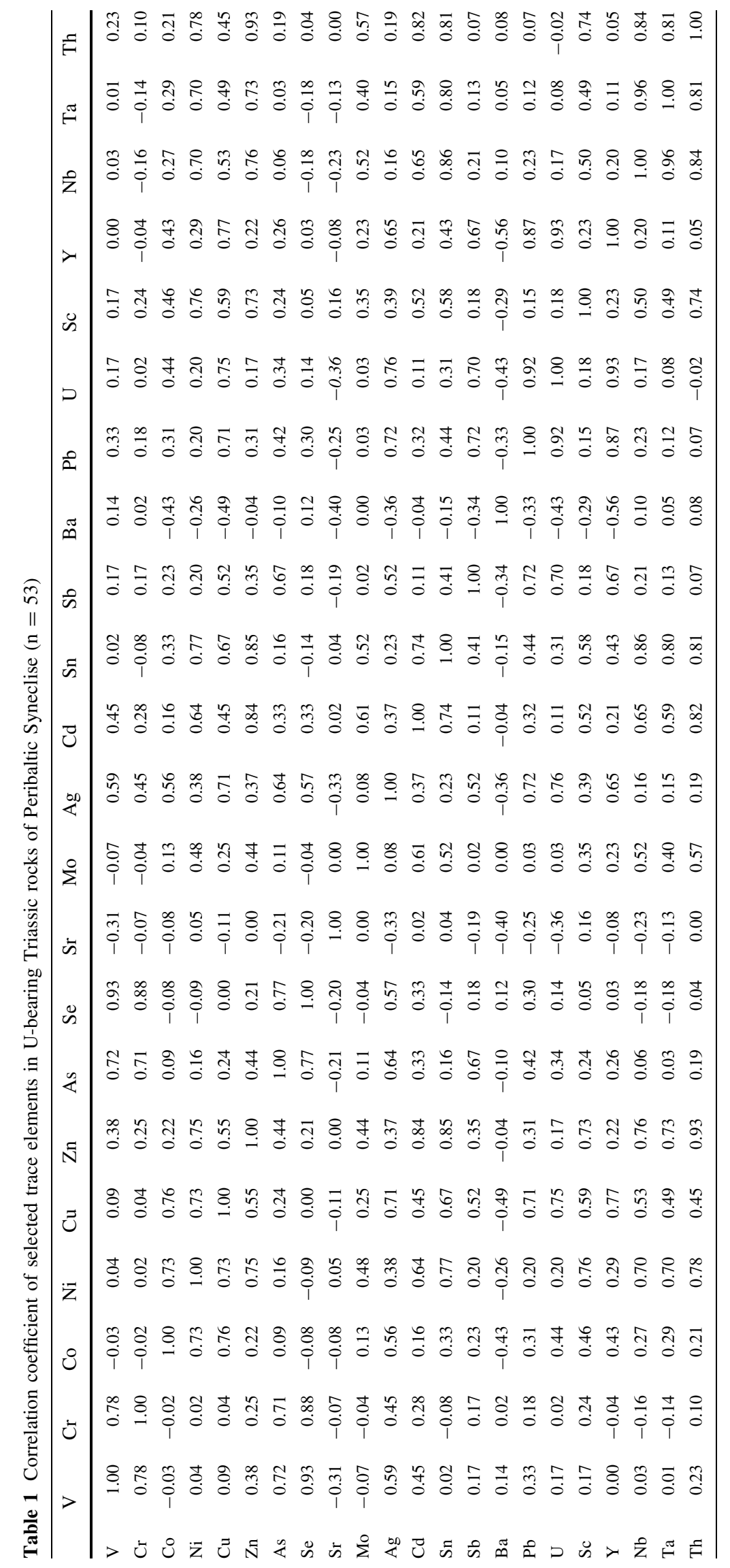


poorly cemented sandstones. From the main components of rocks uranium showed a positive and significant correlation only with $\mathrm{P}_{2} \mathrm{O}_{5}$ (Table 2).

Vanadium showed the strongest correlation with selenium (0.93), chromium (0.78), and arsenic (0.72) and slightly weaker with silver (0.59), cadmium (0.45) and zinc (0.38). From the main components of rock showed positive correlated with $\mathrm{TiO}_{2}(0.52)$, whereas showed significant negative correlations with $\mathrm{CaO}(-0.37)$. Selenium had a strong correlation with vanadium, chromium (0.88), arsenic (0.77) and silver (0.57). Lead had a very strong correlation with uranium (0.92) and yttrium (0.87), slightly lower correlations with silver and antimony (0.72), copper $(0.71)$, tin (0.44), and arsenic (0.42). From the main components of rocks lead showed a positive and significant correlation with $\mathrm{P}_{2} \mathrm{O}_{5}$ and $\mathrm{Na}_{2} \mathrm{O}$.

Thorium had a numerous and relatively high correlations ranging from 0.93 to 0.45 , with such elements zinc, nickel, copper, molybdenum, cadmium, tin, scandium, yttrium, niobium and tantalum. The significant part this was due to the presence of dark accessory minerals in studied rocks. This was also confirmed by numerous positive thorium correlations with the main components of rocks, such as $\mathrm{TiO}_{2}, \mathrm{Al}_{2} \mathrm{O}_{3}, \mathrm{~K}_{2} \mathrm{O}, \mathrm{MgO}$ and $\mathrm{Fe}_{2} \mathrm{O}_{3}$, and a significant negative correlation with $\mathrm{CaO}$, which component was largely in the form of carbonate, epigenetic cement (Table 2).

\section{Experimental}

\section{Reagents and solutions}

The chemicals and reagents used in these studies were used as received. Uranyl nitrate of analytical reagent grade were supplied by Chemapol Praha. The extracting agents: tributylphosphate (TBP), di (2-ethylhexyl)phosphoric acid (D2EHPA), trioctylphosphine oxide (TOPO), triethylamine (TEA), tri- $n$ octylamine (TnOA) and kerosene were Aldrich products. All other reagents used were analytical or reagent grade.

A model solution of uranium was prepared by dissolving a fixed amount of $\mathrm{UO}_{2}\left(\mathrm{NO}_{3}\right)_{2} \cdot 6 \mathrm{H}_{2} \mathrm{O}$ in $5 \%$ sulfuric acid.

\section{Uranium leach solution}

The uranium liquors (sulphuric and carbonate) used in the experiments were obtained by leaching Polish uranium ores: Triassic sandstones using sulphuric acid or sodium carbonate and bicarbonate solution [10, 11]. The leaching liquors contained the following metals:

Table 2 Correlation coefficient of selected trace elements and main components in U-bearing Triassic rocks of Peribaltic Syneclise $(\mathrm{n}=53)$

\begin{tabular}{|c|c|c|c|c|c|c|c|c|c|c|c|c|c|c|}
\hline & $\mathrm{SiO}_{2}$ & $\mathrm{TiO}_{2}$ & $\mathrm{Al}_{2} \mathrm{O}_{3}$ & $\mathrm{Fe}_{2} \mathrm{O}_{3}$ & $\mathrm{MnO}$ & $\mathrm{MgO}$ & $\mathrm{CaO}$ & $\mathrm{Na}_{2} \mathrm{O}$ & $\mathrm{K}_{2} \mathrm{O}$ & $\mathrm{P}_{2} \mathrm{O}_{5}$ & $\left(\mathrm{SO}_{3}\right)$ & $(\mathrm{Cl})$ & $(\mathrm{F})$ & LOI \\
\hline V & 0.33 & 0.52 & 0.19 & -0.04 & -0.31 & -0.14 & -0.37 & 0.25 & 0.23 & 0.23 & -0.09 & 0.50 & -0.29 & -0.34 \\
\hline $\mathrm{Se}$ & 0.21 & 0.35 & 0.00 & -0.06 & -0.15 & -0.14 & -0.20 & 0.13 & 0.05 & 0.20 & -0.09 & 0.38 & -0.19 & -0.20 \\
\hline $\mathrm{Ag}$ & 0.20 & 0.52 & 0.17 & 0.18 & -0.19 & 0.16 & -0.34 & 0.26 & 0.22 & 0.66 & 0.39 & 0.41 & -0.47 & -0.27 \\
\hline $\mathrm{Pb}$ & 0.25 & 0.22 & 0.21 & 0.03 & -0.30 & -0.09 & -0.35 & 0.37 & 0.29 & 0.40 & -0.05 & 0.44 & -0.34 & -0.29 \\
\hline $\mathrm{U}$ & 0.26 & 0.23 & 0.07 & 0.05 & -0.25 & -0.06 & -0.33 & 0.33 & 0.20 & 0.55 & 0.16 & 0.40 & -0.35 & -0.30 \\
\hline Th & 0.02 & 0.76 & 0.92 & 0.49 & -0.33 & 0.47 & -0.39 & 0.13 & 0.65 & 0.35 & 0.10 & 0.11 & -0.55 & -0.17 \\
\hline $\mathrm{SiO}_{2}$ & 1.00 & 0.38 & 0.23 & -0.36 & -0.90 & -0.56 & -0.91 & 0.87 & 0.66 & 0.12 & -0.19 & 0.83 & -0.32 & -0.98 \\
\hline $\mathrm{TiO}_{2}$ & 0.38 & 1.00 & 0.67 & 0.32 & -0.53 & 0.18 & -0.63 & 0.39 & 0.63 & 0.70 & 0.25 & 0.41 & -0.66 & -0.51 \\
\hline $\mathrm{Al}_{2} \mathrm{O}_{3}$ & 0.23 & 0.67 & 1.00 & 0.44 & -0.55 & 0.33 & -0.59 & 0.42 & 0.86 & 0.25 & -0.06 & 0.29 & -0.60 & -0.38 \\
\hline $\mathrm{Fe}_{2} \mathrm{O}_{3}$ & -0.36 & 0.32 & 0.44 & 1.00 & 0.08 & 0.44 & 0.04 & -0.17 & 0.16 & 0.26 & 0.28 & -0.12 & -0.50 & 0.19 \\
\hline $\mathrm{MnO}$ & -0.90 & -0.53 & -0.55 & 0.08 & 1.00 & 0.36 & 0.96 & -0.85 & -0.85 & -0.17 & 0.19 & -0.78 & 0.53 & 0.94 \\
\hline $\mathrm{MgO}$ & -0.56 & 0.18 & 0.33 & 0.44 & 0.36 & 1.00 & 0.26 & -0.41 & -0.01 & 0.21 & 0.47 & -0.45 & -0.26 & 0.45 \\
\hline $\mathrm{CaO}$ & -0.91 & -0.63 & -0.59 & 0.04 & 0.96 & 0.26 & 1.00 & -0.89 & -0.88 & -0.29 & 0.07 & -0.82 & 0.59 & 0.97 \\
\hline $\mathrm{Na}_{2} \mathrm{O}$ & 0.87 & 0.39 & 0.42 & -0.17 & -0.85 & -0.41 & -0.89 & 1.00 & 0.78 & 0.20 & -0.12 & 0.78 & -0.45 & -0.90 \\
\hline $\mathrm{K}_{2} \mathrm{O}$ & 0.66 & 0.63 & 0.86 & 0.16 & -0.85 & -0.01 & -0.88 & 0.78 & 1.00 & 0.23 & -0.12 & 0.61 & -0.60 & -0.77 \\
\hline $\mathrm{P}_{2} \mathrm{O}_{5}$ & 0.12 & 0.70 & 0.25 & 0.26 & -0.17 & 0.21 & -0.29 & 0.20 & 0.23 & 1.00 & 0.37 & 0.11 & -0.46 & -0.22 \\
\hline$\left(\mathrm{SO}_{3}\right)$ & -0.19 & 0.25 & -0.06 & 0.28 & 0.19 & 0.47 & 0.07 & -0.12 & -0.12 & 0.37 & 1.00 & -0.05 & -0.26 & 0.11 \\
\hline$(\mathrm{Cl})$ & 0.83 & 0.41 & 0.29 & -0.12 & -0.78 & -0.45 & -0.82 & 0.78 & 0.61 & 0.11 & -0.05 & 1.00 & -0.36 & -0.84 \\
\hline (F) & -0.32 & -0.66 & -0.60 & -0.50 & 0.53 & -0.26 & 0.59 & -0.45 & -0.60 & -0.46 & -0.26 & -0.36 & 1.00 & 0.46 \\
\hline LOI & -0.98 & -0.51 & -0.38 & 0.19 & 0.94 & 0.45 & 0.97 & -0.90 & -0.77 & -0.22 & 0.11 & -0.84 & 0.46 & 1.00 \\
\hline
\end{tabular}


(1) The solution obtained after sulphuric acid leaching: $\mathrm{U}: 25.32 \mu \mathrm{g} \mathrm{ml}^{-1}$, Th:0.06 $\mu \mathrm{g} \mathrm{ml}^{-1}, \mathrm{Cu}: 0.53 \mu \mathrm{g} \mathrm{ml}^{-1}$, Co:15.00 $\mu \mathrm{g} \mathrm{ml}^{-1}, \mathrm{Mn}: 4.75 \mu \mathrm{g} \mathrm{ml}^{-1}, \mathrm{Zn}: 3.88 \mu \mathrm{g} \mathrm{ml}^{-1}$, Cr:1.83 $\mu \mathrm{g} \mathrm{ml}^{-1}, \quad \mathrm{La}: 0.20 \mu \mathrm{g} \mathrm{ml}^{-1}, \quad \mathrm{~V}: 3.04 \mu \mathrm{g} \mathrm{ml}^{-1}$, $\mathrm{Yb}: 0.02 \mu \mathrm{g} \mathrm{ml}^{-1}$, Ni:1.04 $\mathrm{g} \mathrm{ml}^{-1}$, Fe:71.18 $\mu \mathrm{g} \mathrm{ml}^{-1}$.

(2) The solution obtained after alkaline leaching: $\mathrm{U}: 19.24 \mu \mathrm{g} \mathrm{ml}^{-1}, \mathrm{Mn}: 0.13 \mu \mathrm{g} \mathrm{ml}^{-1}, \mathrm{Zn}: 0.37 \mu \mathrm{g} \mathrm{ml}^{-1}$, $\mathrm{V}: 0.58 \mu \mathrm{g} \mathrm{ml}^{-1}$.

\section{Extraction/stripping experiments}

The extraction and stripping experiments were carried out in plastic (polypropylene) or glass tubes under mechanical agitation $(500 \mathrm{rpm})$, at room temperature $\left(25 \pm 2{ }^{\circ} \mathrm{C}\right)$. Kinetic studies showed that extraction equilibrium was reached after ca. 15 min. However, in all extraction and stripping experiments a contact time of 30 min was chosen for ensuring that the equilibrium was reached. The organic:aqueous phase volume ratio variation was fixed at $1: 1$. The organic phase used as a solvent for extraction was composed of kerosene as diluent for extracting agents. The acidity of aqueous phase (post-leaching liquors) before extraction experiments was adjusted to $\mathrm{pH}$ that was indicated in Table 3 by using $2 \mathrm{M} \mathrm{H}_{2} \mathrm{SO}_{4}$. Following phase contact and reaching equilibrium, the aqueous and organic phases were separated by means of separation funnel and then analysed by inductively coupled plasma mass spectrometry (ICP-MS) [12].

The extraction efficiency $(\% E)$ was calculated by the formula (1):

$\% E=100 D_{\mathrm{c}} /\left(D_{\mathrm{c}}+V_{\mathrm{aq}} / V_{\text {org }}\right)$

where $D_{\mathrm{c}}$ is the distribution ratio, defined as the ratio of concentration of metal in organic phase over its concentration in aqueous phase, $V_{\mathrm{aq}}$-aqueous phase volume, $V_{\text {org }}$-organic phase volume [2]:
The stripping percentage, $\% S$ was determined by the relationship (2):

$\% S=100 D_{\mathrm{s}} /\left(D_{\mathrm{s}}+V_{\mathrm{aq}} / V_{\text {org }}\right)$

where $D_{\mathrm{s}}$ is the distribution ratio of metal in stripping phase over its concentration in organic phase [2].

$\% R$ percent of recovery of uranium in extraction/stripping process was determined by the relationship (3):

$\% R=[$ Metal in the stripping phase $] /$

[Metal in post - leaching liquor] $\cdot 100 \%$

The all experiments were repeated several times in order to confirm the correctness of the obtained results. The relative errors were no more than $5 \%$.

\section{Analysis}

The concentration of selected ions in the aqueous phase was determined by inductively coupled plasma mass spectrometry (ICP-MS) after diluting with $\mathrm{H}_{2} \mathrm{O}$ and $\mathrm{HNO}_{3}$ to the concentration suitable for ICP-measurement. The ICP-MS instrument ELAN DRC II (Perkin Elmer) with cross-flow nebulizer with Scott double-pass spray chamber and $\mathrm{Ni}$ cones was used.

During experiments $\mathrm{pH}$ was monitored using, IoLine $\mathrm{pH}$ combination electrode (type IL-MICRO-pHT-A-BNC-N) coupled with the Schott multiparameter measuring instrument ProLab 4000.

\section{Results and discussion}

The aim of preliminary studies was a selection of the extracting agents and extraction conditions appropriate for the recovery of uranium from post-leaching liquors. The effect of the type of extractant, sulphuric acid and uranium
Table 3 Effect of extractant concentration and $\mathrm{pH}$ of initial aqueous phase on uranium extraction and stripping efficiencies

\begin{tabular}{|c|c|c|c|c|c|c|c|c|c|}
\hline \multirow[t]{3}{*}{ Entry } & \multirow{2}{*}{\multicolumn{3}{|c|}{ Extraction }} & \multicolumn{6}{|c|}{ Stripping } \\
\hline & & & & \multicolumn{2}{|c|}{$0.5 \mathrm{M} \mathrm{Na}_{2} \mathrm{CO}_{3}$} & \multicolumn{2}{|c|}{$0.5 \mathrm{M}\left(\mathrm{NH}_{4}\right)_{2} \mathrm{CO}_{3}$} & \multicolumn{2}{|c|}{$7 \mathrm{M} \mathrm{H}_{2} \mathrm{SO}_{4}$} \\
\hline & [D2EHPA]:[TBP] & $\mathrm{PH}$ & $\% \mathrm{E}$ & $\% \mathrm{~S}$ & $\% \mathrm{R}$ & $\% \mathrm{~S}$ & $\% \mathrm{R}$ & $\% \mathrm{~S}$ & $\% \mathrm{R}$ \\
\hline 1 & $0.2 \mathrm{M}: 0.2 \mathrm{M}$ & 6 & 99 & \multicolumn{4}{|c|}{ Third phase was forming } & - & - \\
\hline 2 & $0.2 \mathrm{M}: 0.2 \mathrm{M}$ & 3 & 99 & 88 & 87 & 97 & 96 & 29 & 28 \\
\hline 3 & $0.2 \mathrm{M}: 0.2 \mathrm{M}$ & 1 & 99 & 93 & 92 & 94 & 93 & - & - \\
\hline 4 & $0.2 \mathrm{M}: 0.07 \mathrm{M}$ & 10 & & \multicolumn{6}{|c|}{ Emulsion } \\
\hline 5 & $0.2 \mathrm{M}: 0.07 \mathrm{M}$ & 6 & 99 & \multicolumn{4}{|c|}{ Third phase was forming } & - & - \\
\hline 6 & $0.2 \mathrm{M}: 0.07 \mathrm{M}$ & 1 & 99 & \multicolumn{4}{|c|}{ Third phase was forming } & 34 & 33 \\
\hline 7 & $0.1 \mathrm{M}: 0.1 \mathrm{M}$ & 6 & 83 & 64 & 55 & 82 & 71 & 47 & 41 \\
\hline 8 & $0.1 \mathrm{M}: 0.1 \mathrm{M}$ & 1 & 99 & $99^{\mathrm{a}}$ & 98 & $99^{\mathrm{a}}$ & 98 & 65 & 64 \\
\hline
\end{tabular}

2 days were needed for separation aqueous and organic phases 
concentrations on the extraction process from model solutions containing uranium was investigated. The extracting agents, like e.g.: tributylphosphate (TBP), di (2ethylhexyl) phosphoric acid (D2EHPA), trioctylphosphine oxide (TOPO), triethylamine (TEA) and tri- $n$-octylamine (TnOA) (Fig. 6) were tested with the model uranium solutions. Then, the recovery of uranium from post-leaching liquors by solvent extraction followed by stripping to aqueous phase was examined. The mixture of D2EHPA and TBP was found as a good extractant for uranium and the studies of extraction of uranium from ore-leaching liquors (sulphuric and carbonate) were carried out. The use a different reagents as strip solutions for uranium in organic phase was also investigated.

\section{Effect of time}

In order to determine the extraction kinetics for different extractants, the time dependence of the extraction efficiency of uranium was investigated and the results are plotted in Fig. 7. The extraction equilibrium was reached within 15 min for all the extractants tested.

\section{Effect of type of extractant}

The tested organic solvents extracted uranium with different efficiency; according to $\% E$ they can be arranged in the following order (Fig. 7):

TnOA $>$ D2EHPA $>$ TOPO $>$ TBP $>$ TEA

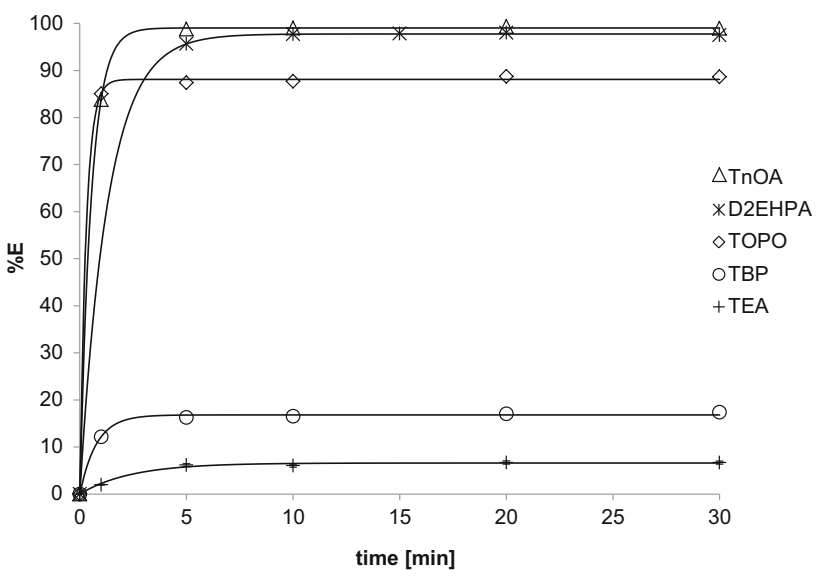

Fig. 7 Time dependence of extraction efficiency of uranium for different extractants: $0.2 \mathrm{M}$ (D2EHPA, TOPO, TEA, TBP, TnOA) in kerosene. The feed solution: $0.2 \mathrm{~g} \mathrm{U}^{-1}$ in $5 \% \mathrm{H}_{2} \mathrm{SO}_{4}, T=25{ }^{\circ} \mathrm{C}$, $V_{\text {aq }} / V_{\text {org }}=1$

Base on the above findings, two extractants: TnOA and D2EHPA were selected for extraction of uranium from post-leaching liquor. They were examined with the purpose of further stripping experiments. The results showed that uranium was extracted from the solution obtained after sulphuric acid leaching with high efficiency as expected (99\% for D2EHPA and $98 \%$ for TnOA). The yield of extraction of some metals other than uranium was also high (Th: $99 \%$, Yb: $99 \%$ for D2EHPA and Th: $51 \%$, V: $68 \%$ for $\mathrm{TnOA}$ ).
Fig. 6 The extracting agents tested for the separation of uranium from the solution<smiles>CCCCOP(=O)(OCCCC)OCCCC</smiles>

TBP<smiles>CCCCCCCCP(=O)(CCCCCCCC)CCCCCCCC</smiles><smiles>CCCCC(CC)COP(=O)(O)OCC(CC)CCCC</smiles>

D2EHPA<smiles>CCN(CC)CC</smiles>

TEA

TOPO<smiles>CCCCCCCCN(CCCCCCCC)CCCCCCCC</smiles>

TnOA 
Effect of sulphuric acid, uranium and extractant concentrations

Figure 8 presents the extraction efficiency of uranium at different concentration of sulphuric acid. The experiments were performed for two initial concentrations of uranium: 0.2 and $0.5 \mathrm{~g} \mathrm{l}^{-1}$ and two molar concentrations of TnOA: $0.2 \mathrm{M}$ and $0.4 \mathrm{M}$. The results showed that the distribution ratios increase with the increase of extractants concentrations while they decrease with the increase of sulphuric acid concentration. The observed effect of decreased distribution ratios with increased acid concentration and increased distribution ratios with increased extractants (like e.g.: TBP, D2EHP) concentration was reported previously [13].

\section{Effect of aqueous/organic phase volume ratio}

Another process variable investigated was the aqueous/ organic phase volume ratio. This study was carried out with $0.2 \mathrm{M}$ TnOA as an extracting agent. The results showed that the efficiencies of extraction decreases with increasing aqueous/organic phase volume ratio (Fig. 9). Thus ratio of 1:1 was used for further studies of liquid-liquid extraction of uranium.

\section{Stripping of uranium}

Once the metal ions have been extracted by the organic phase, they should be stripped back by an aqueous phase. The experiments revealed that the stripping of uranium from organic phase containing D2EHPA with sodium carbonate was not possible because of the separation of $\mathrm{NaD} 2 \mathrm{EHP}$ in a third phase. On the other hand, the efficiency of the stripping from organic phase containing

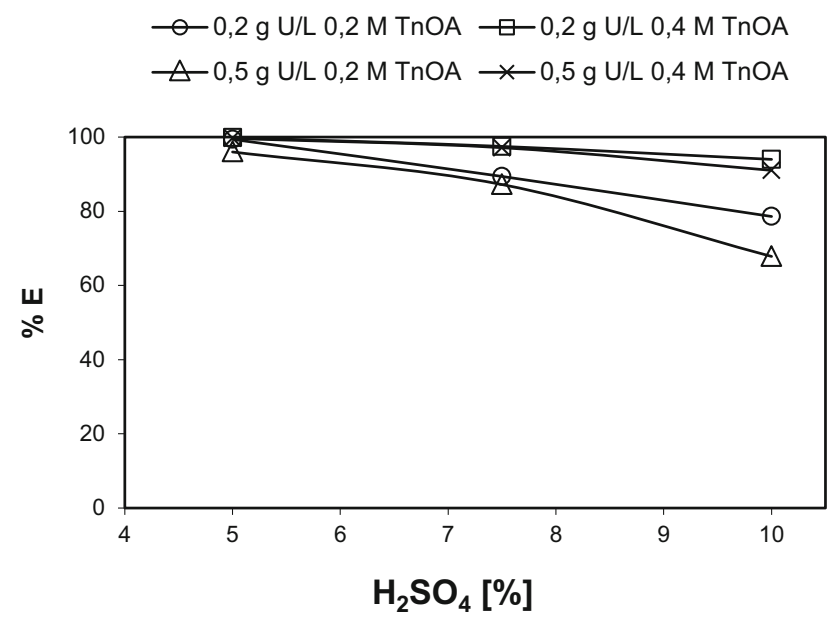

Fig. 8 Effect of $\mathrm{H}_{2} \mathrm{SO}_{4}$ concentration on the extraction of uranium by TnOA in kerosene from $\mathrm{H}_{2} \mathrm{SO}_{4}, T=25^{\circ} \mathrm{C}, V_{\mathrm{aq}} / V_{\text {org }}=1$

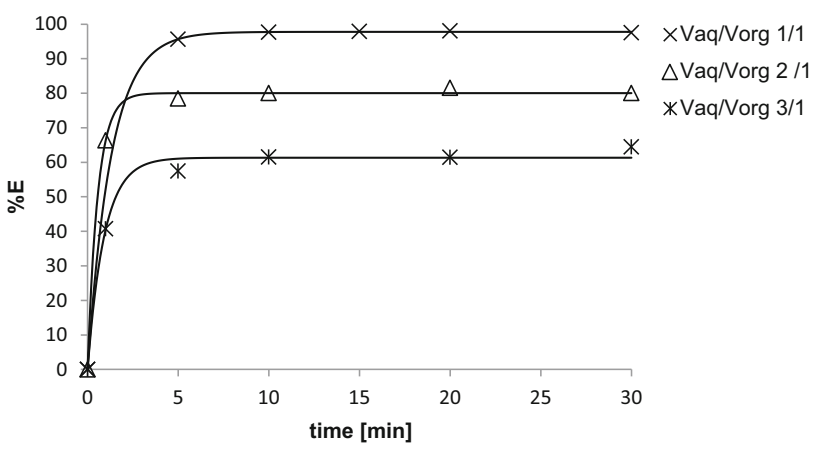

Fig. 9 Effect of aqueous to organic phase volume ratio on the extraction of uranium by $0.2 \mathrm{M} \mathrm{TnOA}$ in kerosene from $5 \% \mathrm{H}_{2} \mathrm{SO}_{4}$; $T=25{ }^{\circ} \mathrm{C}, V_{\text {aq }} / V_{\text {org }}$ volume ratio between aqueous phase and organic phase

TnOA was not satisfactory; it was only 5-11\%. The further research showed that it was possible to avoid the third phase formation when the extractions were carried out with a synergistic mixture D2EHPA and TBP. The obtained results were very promising; the stripping was very efficient and almost complete back extraction of uranium was observed as it was shown below in Table 3.

\section{Effect of synergistic reagent and $\mathrm{pH}$ on extraction and stripping of uranium from the pregnant leach solutions}

In order to choice of the extractant composition to be used in the extraction study of pregnant leach solutions, the solution of extractant were prepared in the following concentration: [D2EHPA]:[TBP] 0.2 M:0.2 M, 0.2 M:0.07 M, $0.1 \mathrm{M}: 0.1 \mathrm{M}$. The extraction percentages for different concentration of extractants are shown in Table 3. It was found that the optimal [D2EHPA]:[TBP] ratio is 0.2 M:0.2 $\mathrm{M}$ at $\mathrm{pH} 1$ (entry 3). The higher $\mathrm{pH}$ is not recommended because the efficiency of stripping process is lower (entry 2). Using of lower concentration of reagents resulted in more difficult separation of phases during stripping experiment. The separation required long time (2 days) (entry 8) or was even impossible (entry 5 and 6). It worth to note that the summarized yield of extraction and stripping experiments $(\% R)$ reached even $98 \%$ (entry 8). The use of sodium and ammonium carbonates as a stripping reagents is more preferable than using sulphuric acid.

The extraction/stripping process of alkaline and acidic post-leaching liquors is illustrated in the Fig. 10. For this process apart from uranium, the extraction/stripping of the other elements were also examined. It worth to be noticed the purification of uranium from alkaline post-leaching liquor was almost completely. After the extraction step, only trace amounts of vanadium were present in organic phase. The stripping step gave pure uranium solution 


\section{A}

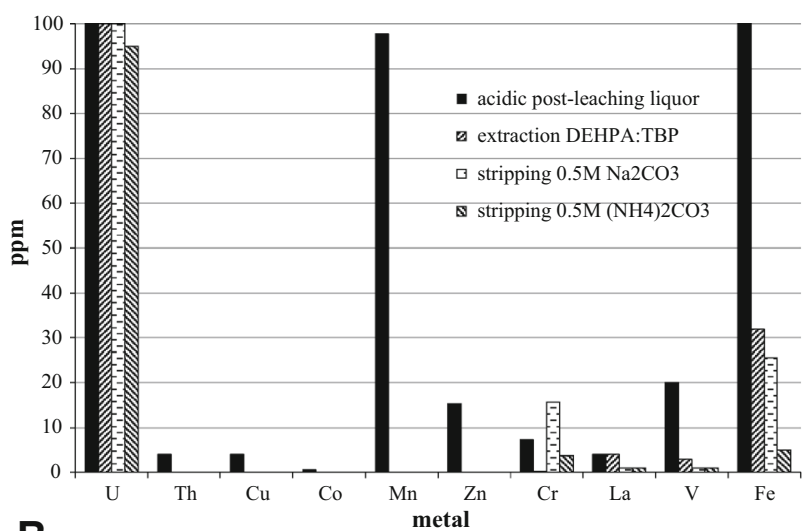

B

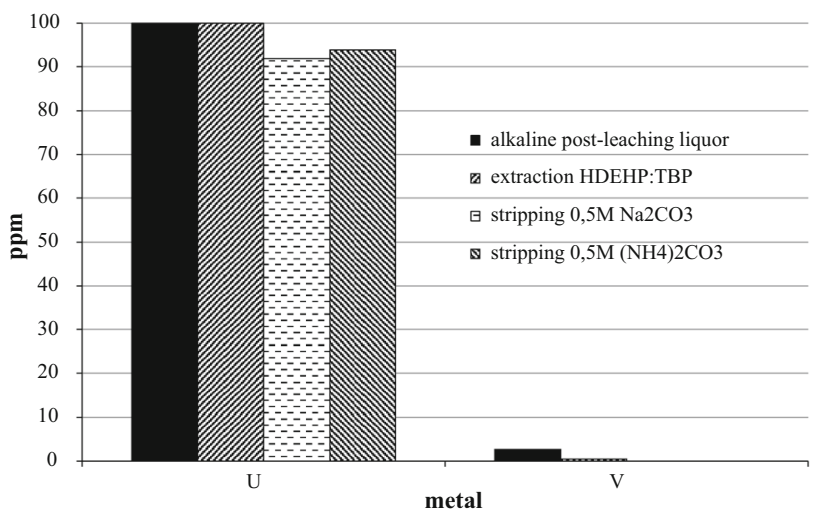

Fig. 10 Extraction and stripping efficiencies of metals from: a acidic post-leaching liquor and $\mathbf{b}$ alkaline post-leaching liquor. Conditions: kerosene, $V_{\text {aq }} / V_{\text {org }} 1: 1$, [D2EHPA]:[TBP] $0.2 \mathrm{M}: 0.2 \mathrm{M}, T=25^{\circ} \mathrm{C}$

(Fig. 10a). The separation of uranium from accompanying metals from acid leaching solution was only partial (Fig. 10b). The highest extraction, stripping and recovery were obtained for uranium but in solution small amounts of other metals as lanthanum, vanadium and iron were detected.

Currently, not much solvent extraction methods have been reported for uranium recovery from alkaline postleaching solutions. A number of quaternary amines were examined for recovery of uranium from carbonate leach solution but results were not satisfying. The common problem was the third phase formation. The solution of this problem was the extraction with an organic system comprising Aliquat 336 and isodecanol in Shellsol D70 [14]. The presented extraction of the pre-acidified alkaline postleaching solution using synergestic mixture HDEHP-TBP mixture might be an alternative to the previously described system.

Further research may give more information about the mechanism of uranium extraction from post-leaching liquors by using organic extracting agents. Structural studies by such methods like XAFS [15-20] could give more information about the coordination environment of uranium reaction with the extractant.

\section{Conclusions}

The synergestic extractant D2EHPA-TBP in kerosene as a diluent was used for recovery of uranium from the solutions obtained after leaching Polish uranium ores. The addition of TBP into the organic phase was found to be essential for preventing the formation of a third phase during the alkali treatment of a solvent containing D2EHPA. An organic phase composed of 0.2 M D2EHPA and 0.2 M TBP with kerosene as diluent is optimal for extraction of uranium at $\mathrm{pH} 1$ and room temperature. The stripping of organic phase is very efficient with $0.5 \mathrm{M}$ ammonium (or sodium) carbonate solution. The recovery of uranium reached even $98 \%$. High-purity uranium is recovered from the alkaline post-leaching liquor. However the single, one-stage extraction of uranium from acidic post-leaching liquors is not sufficient to separate pure uranium. The solvent extraction is a part of the research on the possibility of uranium extraction from domestic resources in Poland. It will be followed by ammonium or sodium diuranate precipitation, the precursors of yellow cake- $\mathrm{U}_{3} \mathrm{O}_{8}$.

Acknowledgments The studies were supported by POIG 01.01.0214-094-09-00 research grant: "Analysis of the possibility of uranium supply from domestic resources", the financial resources for science in the years 2015-2016 granted for the implementation of the international project co-financed W-84/IAEA/2015 and IAEA Research Contract No: 18542 . The authors wish to thank dr. E. Chajduk for her valuable help in carrying out the chemical analysis of aqueous solutions.

Open Access This article is distributed under the terms of the Creative Commons Attribution 4.0 International License (http://crea tivecommons.org/licenses/by/4.0/), which permits unrestricted use, distribution, and reproduction in any medium, provided you give appropriate credit to the original author(s) and the source, provide a link to the Creative Commons license, and indicate if changes were made.

\section{References}

1. Edwards CR, Oliver AJ (2000) Uranium processing: a review of current methods and technology. JOM 52:12-20

2. Kumar JR, Kim JS, Lee JY, Yoon HSA (2014) Brief review on solvent extraction of uranium form acidic solutions. Sep Purif Rev. 40(2):77-125

3. Kiegiel K, Steczek L, Zakrzewska-Trznadel G (2013) Application of Calixarenes as macrocyclic ligands for uranium(VI): a review. J. Chem. doi:10.1155/2013/762819

4. El Hady SM, Bakry AR, Al Shami AAS, Fawzy MM (2016) Processing of the xenotime concentrate of Southwesterrn Sinai 
via alkali fusion and solvent extraction. Hydrometallurgy 163:115-119

5. Musikas C, Schulz WW, Rydberg J, Choppin GR (1992) Principles and practices of solvent extraction. Marcel Dekker, New York, pp 413-447

6. Khorfan S, Shino O, Wahoud A, Dahdouh A (2000) Stripping of uranium from D2EHPA/TOPO solvent by ammonium carbonate solutions. Periodica Polytechnica Ser Chem Eng. 44(2):123-132

7. Daoud JA, Zeid MM, Aly HF (1997) Tetravalent uranium extraction by HDEHP in kerosene from phosphate medium. Solv Extr Ion Exch 15(2):203-217

8. Miecznik JB, Strzelecki R, Wolkowicz S (2011) Uranium in Poland-history of prospecting and chances for finding new deposits. Prz Geol. 59:688-697

9. Smakowski T, Wolkowicz S, Miecznik JB (2013) Possible sources of nuclear fuel supply for potential nuclear power plants in Poland. Zesz Nauk IGSMiE PAN. 85:295-306

10. Frackiewicz K, Kiegiel K, Herdzik-Konecko I, Chajduk E, Zakrzewska-Trznadel G, Wolkowicz S, Chwastowska J, Bartosiewicz I (2012) Extraction of uranium from low-grade Polish ores: dictyonemic shales and sandstones. Nukleonika. 58: 451-459

11. Gajda D, Kiegiel K, Zakrzewska- Kołtuniewicz G, Chajduk E, Wołkowicz S (2015) Mineralogy and uranium leaching of ores from Triassic Peribaltic sandstones. J Radioanal Nucl Chem 303:521-529

12. Chajduk E, Bartosiewicz I, Pyszynska M, Chwastowska J, Polkowska-Motrenko H (2013) Determination of uranium and selected elements in Polish dictyonema shales and sandstones by ICP-MS. J Radioanal Nucl Chem 295:1913-1919

13. Gindler JE (1962) The radiochemistry of Uranium. Nuclear Science Series NAS-NS-3050. http://www.osti.gov/bridge/purl. cover.jsp?purl=/5392883-T13fMD/
14. Zhu Z, Pranolo Y, Cheng ChY (2013) Uranium solvent extraction and separation from vanadium. Sep Sci Technol 48:1402-1408

15. Schmeide K, Sachs S, Bubner M, Reich T, Heise T, Heinz KH, Bernhard G (2003) Interaction of uranium(VI) with various modified and unmodified natural and synthetic humic substances studied by EXAFS and FTIR spectroscopy. Inorg Chimica Acta. 351:133-140

16. Sheng G, Shao X, Li Y, Li J, Dong H, Cheng W, Gao X, Huang Y (2014) Enhanced removal of uranium(VI) by nanoscale zerovalent iron supported on $\mathrm{Na}$-bentonite and an investigation of mechanism. J Phys Chem A 118:2952-2958

17. Sheng G, Yang Q, Peng F, Li H, Gao X, Huang Y (2014) Determination of colloidal pyrolusite, $\mathrm{Eu}(\mathrm{III})$ and humic substance interaction: a combined batch and EXAFS approach. Chem Eng J 245:10-16

18. Sheng G, Alsaedi A, Shammakh W, Monaquel S, Sheng J, Wang X, Li H, Huang Y (2016) Enhanced sequestration of selenite in water by nanoscale zero valent iron immobilization on carbon nanotubes by a combined batch, XPS and XAFS investigation. Carbon 99:123-130

19. Sheng G, Tang Y, Linghu W, Wang L, Li J, Li H, Wang X, Huang Y (2016) Enhanced immobilization of $\mathrm{ReO}_{4}{ }^{-}$by nanoscale zerovalent iron supported on layered double hydroxide via an advanced XAFS approach: implications for $\mathrm{TcO}_{4}{ }^{-}$sequestration. Appl Catal B 195:268-276

20. Sheng G, Hu J, Li H, Li J, Huang Y (2016) Enhanced sequestration of $\mathrm{Cr}(\mathrm{VI})$ by nanoscale zero-valent iron supported on layered double hydroxide by batch and XAFS study. Chemosphere 148:227-232 